\title{
Understanding the Interrelationship between Education, Income, and Obesity among Adults in Saudi Arabia
}

\author{
Hala H. Moslia Hebah A. Kutbi ${ }^{b}$ Ahmed H. Alhasanc Rana H. Moslib \\ aDivision of Endocrinology and Metabolism, Department of Internal Medicine, Faculty of \\ Medicine, King Abdulaziz University, Jeddah, Saudi Arabia; ${ }^{b}$ Clinical Nutrition Department, \\ Faculty of Applied Medical Sciences, King Abdulaziz University, Jeddah, Saudi Arabia; \\ ${ }^{c}$ College of Medicine, University of Jeddah, Jeddah, Saudi Arabia
}

\section{Keywords}

Obesity $\cdot$ Obesity status $\cdot$ Education $\cdot$ Income $\cdot$ Saudi Arabia $\cdot$ Socioeconomic status

\begin{abstract}
Objective: To examine the association of sociodemographic variables with the odds of being obese among adults in Saudi Arabia, and to examine whether or not the association between the educational level and the odds of being obese among adults in Saudi Arabia is modified by the income level. Methods: A total of 3,925 participants were recruited for this crosssectional study. Sociodemographic and anthropometric data were collected using standardized procedures. Unadjusted and adjusted logistic regression models were examined, with a dichotomous obesity status variable as the outcome. Furthermore, an interaction term for income level with educational level was tested and appeared significant. Thus, additional regression models were run in order to examine the association between educational level and obesity status separately among the low- and higher-income groups. Results: Compared to participants with a college degree or higher, illiterate participants and those with an elementary education had higher odds of obesity (OR: $2.76,95 \% \mathrm{Cl}: 1.81-4.22$, and OR: $2.68,95 \% \mathrm{Cl}$ : 1.89-3.82, respectively). However, participants with a low income had lower odds than participants who had a higher income (OR: $0.84,95 \% \mathrm{Cl}: 0.70-0.99)$. Examining the association between educational level and obesity while stratifying by income revealed that a negative association between education and obesity exists among both income groups. However, the magnitude of the ORs was higher among participants with higher income, suggesting a stron-
\end{abstract}


ger association between education and obesity among wealthier individuals. Conclusion: Individuals in the highest income bracket with lower levels of education may have greater odds of obesity. Targeting them in intervention programs is warranted.

(C) 2020 The Author(s)

Published by S. Karger AG, Basel

\section{Introduction}

Overweight and obesity as defined by the World Health Organization (WHO) are a state of increased body fat of varying degrees that could impair health [1]. It has long been known that increased adiposity exposes the individual to a higher risk of developing a plethora of adverse health issues, such as hypertension, dyslipidemia, cerebrovascular stroke, and gallbladder and kidney stones, and diabetes [2-7]. Cardiovascular disease risk is also known to be directly related to the degree of obesity $[8,9]$. More recently, obesity has been linked to an increased risk of various malignancies as well as survivorship from cancer in the form of recurrence, quality of life, as well as long-term prognosis and cancer progression $[10,11]$. Further data show that obesity is implicated in chronic respiratory disorders and sleep disordered breathing [12], musculoskeletal disease and osteoarthritis [13], and all-cause mortality [14].

In the first half of the 20th century, it was believed that overweight and obesity were conditions unique to those of higher socioeconomic status. However, starting from the 1990s, it became more recognized that obesity affects individuals of lower socioeconomic status equally if not more than those of affluence in developing countries $[15,16]$. The more recent trends of increased adiposity among lower-income groups are attributed to the lower costs and convenience of energy-dense food options $[17,18]$. In both developed and developing countries around the world, fast and processed foods and snacks, refined grains, and sugary drinks cost less than lower-energy, healthier food options, such as fresh fruits and vegetables, fresh cuts of lean meats, and seafood $[18,19]$. Moreover, a discrepancy in the educational level between higher- and lower-income groups may also be an independent contributor to the higher obesity risk among less affluent individuals [20]. Higher education was found to be associated with lower consumption of total fats and cholesterol [21] and greater intake of fruits and vegetables $[22,21]$. This positive effect of a better education may operate directly through greater nutritional knowledge, which affects dietary practices [22].

As seen in many developing countries around the world, obesity rates in the Kingdom of Saudi Arabia (KSA) have been on the rise during the past several years [23]. Although the association between sociodemographic factors and obesity risk are well established in several other countries, such as the United States [24], findings from studies conducted on KSA samples are conflicting [25]. For example, while obesity was found to be negatively associated with education among women [25-27], a positive association between maternal education and obesity was observed among Saudi adolescents [26]. Furthermore, while some found that obesity rates were higher among lower-income groups [27], others found that lower-income individuals were less likely to be obese [26].

A clearer understanding of how sociodemographic characteristics are associated with weight status is critical for more effective targeting and design of obesity interventions and public health programs. Therefore, the primary objective of this study was to examine the association of sociodemographic variables, including educational level and income level, with odds of being obese (BMI $\geq 30 \mathrm{~kg} / \mathrm{m}^{2}$ ) among adults in KSA. The secondary objective was to examine whether or not the association between educational level and odds of being obese (BMI $\geq 30 \mathrm{~kg} / \mathrm{m}^{2}$ ) among KSA adults was modified by income level. 


\section{Methods}

\section{Participants and Procedure}

The study included 3,925 participants who were recruited from shopping malls in Jeddah city and surrounding areas, including Makkah and small villages, during a series of public health campaigns conducted over a period of 3 months. Study inclusion criteria were age $\geq 18$ years; fluency in Arabic; and KSA residency. Women reporting that they were pregnant at the time of data collection were also excluded from the study.

Following completion of an informed consent form to participate, research assistants collected sociodemographic and anthropometric data from participants. Due to a high prevalence of low literacy, to assess sociodemographic characteristics, research assistants read aloud questions and corresponding response options; then they entered participants' answers into electronic tablets. Research assistants measured participants' weight and height using standardized procedures [28].

Ethical clearance to perform this study was obtained from the Unit of Biomedical Ethics at the King Abdulaziz University Hospital, and confidentiality was maintained as data remained anonymous for all participants.

\section{Measures}

Primary Predictors: Sociodemographic Characteristics

Information gathered included participant's sex (male vs. female); nationality (Saudi vs. non-Saudi); educational level (illiterate, elementary school, middle school, high school, 2-year diploma, bachelor's degree, and graduate degree) (later collapsed into only 5 categories); total monthly income (no income, $<5,000,5,000-10,000,10,000-20,000$, or $\geq 20,000$ SAR per month) (later collapsed into only 2 categories: low income, i.e., defined as total monthly income $<5,000$ SAR per month vs. higher income [29]) (1 USD = 3.75 SAR); financial sponsorship (financially supported by someone else, supports one's self, supports one's self and spouse, and supports one's self, spouse, and children) (later collapsed into only 2 categories); marital status (single, married, widowed, and divorced) (later collapsed into only 2 categories); and current active smoker (yes vs. no).

Primary Outcome: Obesity Status (BMI $\geq 30 \mathrm{~kg} / \mathrm{m}^{2}$ )

BMI was calculated by dividing weight in kilograms by height in centimeters squared. Based on the BMI score, body weight was classified as obese if BMI was $\geq 30 \mathrm{~kg} / \mathrm{m}^{2}$ [30].

\section{Statistical Analysis}

Statistical analyses were conducted using the Statistical Package for Social Sciences (SPSS; version 24.0; Armonk, NY, USA). Descriptive statistics were conducted to assess characteristics of the full sample and bivariate analyses by obesity status; differences in characteristics between the obese group and the nonobese group were examined using $\chi^{2}$ statistics.

To further examine the association between each sociodemographic variable and obesity status, we conducted logistic regression analyses with the dichotomous obesity status variable (BMI $\geq 30 \mathrm{~kg} / \mathrm{m}^{2}$ vs. not) as the outcome. First, separate unadjusted models were examined for each of the primary predictors (i.e., Saudi nationality, educational level, low-income level, financial sponsorship, and marital status). Then, a fully adjusted model including all primary predictors was tested. Since binary analyses showed that the association between sex and obesity status was not significant $(p>0.20)$, we did not include sex in the adjusted regression model.

In order to examine whether the association between educational level and obesity status was modified by income level, we included an interaction term for income level with educa- 
Table 1. Characteristics of the total sample and associations with obesity status $(n=3,925)$

\begin{tabular}{|c|c|c|c|c|}
\hline Characteristics & $\begin{array}{l}\text { Total sample, } \\
n(\%)\end{array}$ & $\begin{array}{l}\text { Obese } \\
\left(\mathrm{BMI} \geq 30 \mathrm{~kg} / \mathrm{m}^{2}\right) \\
(n=1,014), n(\%)\end{array}$ & $\begin{array}{l}\text { Not obese } \\
\left(\mathrm{BMI}<30 \mathrm{~kg} / \mathrm{m}^{2}\right) \\
(n=2,911), n(\%)\end{array}$ & $p$ value \\
\hline Sex & & & & 0.28 \\
\hline Male & $1,716(43.7)$ & $458(45.2)$ & $1,258(43.2)$ & \\
\hline Female & $2,209(56.3)$ & $556(54.8)$ & $1,653(56.8)$ & \\
\hline Nationality & & & & 0.03 \\
\hline Saudi & $2,999(76.4)$ & $800(78.9)$ & $2,199(75.5)$ & \\
\hline Non-Saudi & $926(23.6)$ & $214(21.1)$ & $712(24.5)$ & \\
\hline Education & & & & $<0.01$ \\
\hline Illiterate & $106(2.70)$ & $41(4.00)$ & $65(2.20)$ & \\
\hline Elementary & $157(4.00)$ & $65(6.40)$ & $92(3.20)$ & \\
\hline Middle school & $325(8.30)$ & $92(9.10)$ & $233(8.00)$ & \\
\hline High school or diploma & $1,459(37.2)$ & $370(36.5)$ & $1,089(37.4)$ & \\
\hline College degree or higher & $1,878(47.8)$ & $446(44.0)$ & $1,432(49.2)$ & \\
\hline Total monthly income & & & & $<0.01$ \\
\hline No income & $570(14.5)$ & 130 (12.8) & $440(15.1)$ & \\
\hline$<5,000 \mathrm{SAR}$ & $878(22.4)$ & $195(19.2)$ & $683(23.5)$ & \\
\hline $5,000-10,000$ SAR & $1,188(30.3)$ & $316(31.2)$ & $872(30.0)$ & \\
\hline $10,000-20,000$ SAR & $1,050(26.8)$ & $315(31.1)$ & $735(25.2)$ & \\
\hline$>20,000$ SAR & $239(6.10)$ & $58(5.70)$ & $181(6.20)$ & \\
\hline Financial sponsorship & & & & $<0.01$ \\
\hline Financially supported by someone else & $1,548(39.4)$ & $326(32.1)$ & $1,222(42.0)$ & \\
\hline Financially supports one's self & $1,126(28.7)$ & $269(26.5)$ & 857 (29.4) & \\
\hline Financially supports one's self and spouse & $390(9.90)$ & $115(11.3)$ & $275(9.40)$ & \\
\hline Financially supports one's self, spouse, and children & $861(21.9)$ & $304(30.0)$ & $557(19.1)$ & \\
\hline Marital status & & & & $<0.01$ \\
\hline Single & $1,545(39.4)$ & $224(22.1)$ & $1,321(45.4)$ & \\
\hline Married & $2,136(54.4)$ & $706(69.6)$ & $1,430(49.1)$ & \\
\hline Widowed & $98(2.50)$ & $37(3.60)$ & $61(2.10)$ & \\
\hline Divorced & $146(3.70)$ & $47(4.60)$ & $99(3.40)$ & \\
\hline Smoker & & & & 0.07 \\
\hline Yes & $1,032(26.3)$ & 245 (24.2) & 787 (27.0) & \\
\hline No & 2,893 (73.7) & 769 (75.8) & $2,124(73.0)$ & \\
\hline
\end{tabular}

tional level in the fully adjusted model. Since the interaction term was statistically significant $(p=0.01)$, suggesting that the association between educational level and obesity status may vary by income level, we ran separate adjusted regression models and examined the association between educational level and obesity status separately among the low- and higherincome groups.

\section{Results}

\section{Sample Characteristics and Associations with Obesity Status}

As shown in Table 1, about one-quarter of the sample (25.8\%) was classified as obese; $54.8 \%$ of them were females. About half of the sample $(52.2 \%)$ had only a high school education or less, and about one-third (36.9\%) were considered low income (had a total monthly income of $\leq 5,000$ SAR [29]) (Table 1 ). 
Mosli et al.: Education, Income, and Obesity in Saudi Arabia

Table 2. Unadjusted and adjusted associations between sociodemographic variables and obesity status

\begin{tabular}{|c|c|c|}
\hline & $\begin{array}{l}\text { Unadjusted OR } \\
(95 \% \mathrm{CI})\end{array}$ & $\begin{array}{l}\text { Adjusted }{ }^{1} \text { OR } \\
(95 \% \mathrm{CI})\end{array}$ \\
\hline \multicolumn{3}{|l|}{ Saudi Nationality } \\
\hline Yes & $1.21(1.02-1.44)^{*}$ & $1.21(1.01-1.46)^{*}$ \\
\hline No (reference) & 1 & 1 \\
\hline \multicolumn{3}{|l|}{ Education } \\
\hline Illiterate & $2.03(1.35-3.04)^{* *}$ & $2.76(1.81-4.22)^{* *}$ \\
\hline Elementary & $2.27(1.62-3.17)^{* *}$ & $2.68(1.89-3.82)^{* *}$ \\
\hline Middle school & $1.27(0.97-1.65)$ & $1.53(1.16-2.01)^{* *}$ \\
\hline High school or diploma & $1.09(0.93-1.28)$ & $1.25(1.06-1.48)^{* *}$ \\
\hline College degree or higher (reference) & 1 & 1 \\
\hline \multicolumn{3}{|l|}{ Low income } \\
\hline Yes $(5,000$ SAR per month or less $)$ & $0.75(0.65-0.87)^{* *}$ & $0.84(0.70-0.99)^{*}$ \\
\hline No (reference) & 1 & 1 \\
\hline \multicolumn{3}{|l|}{ Financial sponsorship } \\
\hline Financially sponsored by someone else & $1.53(1.31-1.78)^{* *}$ & $1.33(1.14-1.56)^{* *}$ \\
\hline Not financially sponsored by someone else (reference) & 1 & 1 \\
\hline \multicolumn{3}{|l|}{ Marital status } \\
\hline Single & $0.42(0.36-0.49)^{* *}$ & $0.45(0.39-0.53)^{* *}$ \\
\hline Not single (reference) & 1 & 1 \\
\hline
\end{tabular}

${ }^{1}$ Adjusted for all primary predictors. ${ }^{*} p<0.05 .{ }^{* *} p<0.01$.

The prevalence of obesity was significantly higher among KSA participants (26.6\%) than non-KSA participants (23.1\%). The prevalence of obesity was significantly negatively associated with educational level. Obesity prevalence was $38.7 \%$ among illiterate participants, $41.4 \%$ among participants with an elementary education, $28.3 \%$ among participants with a middle school education, $25.4 \%$ among participants with a high school education, and $23.7 \%$ among participants with a college degree or higher. Furthermore, obesity was significantly associated with total monthly income, such that the prevalence of obesity was lower among low-income participants (22.4\%) and participants making $>20,000$ SAR per month $(24.3 \%)$, compared to those making between 5,000 and 20,000 SAR per month (28.2\%). Prevalence of obesity was also significantly associated with financial sponsorship and marital status. However, no significant association between sex and obesity status was observed $(p>0.10)$, and the association between smoking and obesity only reached marginal significance $(p=$ 0.07) (Table 1).

\section{Adjusted Associations between Sociodemographic Characteristics and Obesity}

As shown in Table 2, KSA participants had higher odds of obesity than non-KSA participants (OR: 1.21, 95\% CI: 1.01-1.46). Compared to participants with a college degree or higher, illiterate participants and those with an elementary education had higher odds of obesity (OR: 2.76, 95\% CI: 1.81-4.22, and OR: 2.68, 95\% CI: 1.89-3.82, respectively). Additionally, participants who were financially sponsored by someone else had higher odds of obesity than those who were not (OR: 1.33, 95\% CI: 1.14-1.56). On the other hand, participants who had a low income (5,000 SAR per month or less) had lower odds of obesity compared to participants who had a higher income (OR: 0.84, 95\% CI: 0.70-0.99). Similarly, participants who were single (i.e., not married) had lower odds of obesity than those who were not single (OR: 0.45, 95\% CI: 0.39-0.53) (Table 2). 
Mosli et al.: Education, Income, and Obesity in Saudi Arabia

Table 3. Adjusted association between educational level and obesity status stratified by income ${ }^{1}$

\begin{tabular}{lll}
\hline & $\begin{array}{l}\text { OR }(95 \% \mathrm{CI}) \\
\text { among low-income } \\
\text { participants } \\
(n=1,448)\end{array}$ & $\begin{array}{l}\text { OR (95\% CI) } \\
\text { among participants } \\
\text { who had no low income } \\
(n=2,477)\end{array}$ \\
\hline $\begin{array}{l}\text { Education } \\
\text { Illiterate }\end{array}$ & $2.29(1.33-3.94)^{* *}$ & $4.46(2.07-9.64)^{* *}$ \\
Elementary & $2.12(1.32-3.39)^{* *}$ & $4.29(2.35-7.84)^{* *}$ \\
Middle school & $1.03(0.66-1.61)$ & $2.15(1.48-3.11)^{* *}$ \\
High school or diploma & $1.23(0.92-1.72)$ & $1.24(1.01-1.50)^{*}$ \\
College degree or higher (reference) & 1 & 1 \\
\hline
\end{tabular}

${ }^{1}$ Adjusted for all primary predictors. ${ }^{*} p<0.05 .{ }^{* *} p<0.01$.

Associations between the Educational Level and Obesity by Income

Examining the association between educational level and obesity status while stratifying by income revealed that the negative association between education and obesity exists among both income groups (group with an income $<5,000$ SAR per month vs. group of higher income). However, the magnitude of the ORs was higher among participants with higher income, suggesting a stronger association between education and obesity among wealthier individuals. Compared to participants with a college degree or higher, odds of obesity among participants who were illiterate was 2.29 (95\% CI: 1.33-3.94) in the low-income group compared to 4.46 (95\% CI: 2.07-9.64) in the higher income group. Odds of obesity among participants who had an elementary school education was 2.12 (95\% CI: 1.32-3.39) in the low-income group compared to 4.29 (95\% CI: 2.35-7.84) in the higher income group (Table 3). In the low-income group, there were no significant differences in the odds of obesity between participants who completed middle or high school and participants with a college degree or higher (OR: 1.03, 95\% CI: 0.66-1.61, and OR: 1.23, 95\% CI: 0.92-1.72, respectively). However, in the higher-income group, participants who only completed middle or high school had significantly higher odds of obesity than participants with a college degree or higher (OR: 2.15, 95\% CI: 1.48-3.11, and OR: 1.24, CI: 1.01-1.50, respectively).

\section{Discussion}

In the present study, a quarter of the sample was classified as obese, an estimate that is quite higher than the WHO 2016 estimation of worldwide adult obesity prevalence of $13 \%$ [1]. We found that obesity prevalence was higher among participants who were KSA residents compared to non-KSA residents ( $24 \%$ of the sample). In agreement with many studies around the world [31], we found that a higher educational level was associated with a lower obesity prevalence. However, contrary to findings from international studies [24, 27], our analysis revealed that the association between income and obesity might not be a negative, monotonic association. Our data rather suggest that the association between income and obesity might be an inverted U-shaped curvilinear association. The prevalence of obesity was lower among low-income participants $(22.4 \%)$ and participants making $>20,000$ SAR per month $(24.3 \%)$ than those making between 5,000 and 20,000 SAR per month $(28.2 \%)$.

Adjusted analyses corroborated these associations, as we found illiterate participants and those with only an elementary education to have higher odds of obesity than participants 
with a college degree or higher. In addition, participants who made $>5,000$ SAR per month had higher odds of obesity, and the odds of obesity was substantially higher among higher income individuals who were less educated. We can, therefore, infer from our results that the greatest group at risk is those in the highest income bracket with lower levels of education. As such, these are the individuals that should be targeted with intensive education and health awareness programs. Moreover, we found that participants who were single were less likely to be obese; a finding that is in line with results from other studies [32].

While KSA is considered an affluent country, a prominent wealth gap exists between lowand high-income families. As in many Arab countries, the wealth of high-income families is often inherited transgenerationally and does not necessarily reflect superior education or employment status [33]. According to the World Bank website, while the population of Saudi Arabia ballooned since the 1960s from around 4 million persons to over 32 million persons in 2015, the GDP suffered a noticeable dip in 2016-2017 but is on the way to recovery [34]. From the national statistics website [35], it appears that the individual household income has overall increased, as did the average expenditure. However, reviewing the categories on which money was spent, it appears that health maintenance, such as gym memberships, counseling, and other health maintenance systems, were not a major source of expenditure [34]. This is concerning and may explain adverse health outcomes presented in individuals at the higher end of the income spectrum. A large percentage of high-income individuals may have inadequate education and may allocate less money and resources to preserve a healthy lifestyle and seek preventative health care services.

Given our findings and the difficulty in reversing obesity once it is a reality, and the wellknown association between obesity and the diseases mentioned earlier, early prevention and intervention would make the most sense both economically and from a population health perspective. To this end, several options can be considered, such as early mass screening programs, national awareness campaigns with obesity and its comorbidities as the main focus, and possibly door-to-door campaigns for early detection and implementation of prevention and/or therapeutic programs. Efforts may specifically target and betailored to address knowledge deficits and other psychosocial factors among high-income individuals who are less educated; awareness programs may be designed aiming to increase allocation of resources to promote a healthy lifestyle. Furthermore, programs may be directed towards other individuals who may have higher odds of obesity, such as those who are married and with a Saudi nationality.

This study has several limitations. First, since this is a cross-sectional study, we cannot infer a causal relationship between low education among high income and higher likelihood of obesity. In addition, behaviors such as dietary intake and physical activity were not measured, and we, therefore, cannot infer that higher-income individuals who are less educated follow a poor lifestyle. Longitudinal studies that follow individuals with different income and educational levels over time while evaluating their lifestyle practices are needed. This study also has several strengths. The large sample size and the high response rate has likely resulted in adequate statistical power to detect significant associations. Additionally, weight and height were objectively measured providing a precise estimate of BMI values. Finally, randomization of data collection and sampling from several areas around the city might have strengthened our ability to demonstrate the association between obesity and sociodemographic characteristics in a representative manner to the residents.

In summary, this study examined the association of sociodemographic variables with odds of being obese. Our findings indicate that lower education and higher income are positively associated with obesity; and that obesity is significantly more common among KSA participants and married individuals than non-KSA residents or singles. Intensive education and health awareness programs should be performed nationwide and target KSA individuals of high income and low levels of education to promote health and well-being. 


\section{Acknowledgment}

The authors would like to thank the VISION Medical Team, Dr. Manal Mohammed Shams, and Ms. Lamis Fahad Basaeed for their assistance.

\section{Statement of Ethics}

This study was approved by the Unit of Biomedical Ethics at the King Abdulaziz University Hospital, and confidentiality was maintained as data remained anonymous for all participants.

\section{Disclosure Statement}

The authors have no conflict of interest to disclose.

\section{Funding Sources}

This research received no specific grant from any funding agency, or commercial or not-for-profit sectors.

\section{Author Contributions}

H.H.M., R.H.M., and H.A.K. designed the study and drafted the initial manuscript. R.H.M. and H.A.K. analyzed the data. H:H.M. and A.H.A. coordinated and supervised data collection, provided input on the analysis plan and critically reviewed the manuscript. All authors have approved the final manuscript as submitted.

\section{References}

1 Yang J, Carmichael SL, Canfield M, Song J, Shaw GM, Study NB; National Birth Defects Prevention Study. Socioeconomic status in relation to selected birth defects in a large multicentered US case-control study. Am J Epidemiol. 2008 Jan;167(2):145-54.

2 Bangalore S, Fayyad R, Laskey R, DeMicco DA, Messerli FH, Waters DD. Body-weight fluctuations and outcomes in coronary disease. N Engl J Med. 2017 Apr;376(14):1332-40.

3 Hägg S, Fall T, Ploner A, Mägi R, Fischer K, Draisma HH, et al.; European Network for Genetic and Genomic Epidemiology Consortium. Adiposity as a cause of cardiovascular disease: a Mendelian randomization study. Int J Epidemiol. 2015 Apr;44(2):578-86.

4 Liu T, Wang W, Ji Y, Wang Y, Liu X, Cao L, et al. Association between different combination of measures for obesity and new-onset gallstone disease. PLoS One. 2018 May;13(5):e0196457.

5 Bray GA, Heisel WE, Afshin A, Jensen MD, Dietz WH, Long M, et al. The science of obesity management: an endocrine society scientific statement. Endocr Rev. 2018 Apr;39(2):79-132.

6 Leong A, Porneala B, Dupuis J, Florez JC, Meigs JB. Type 2 diabetes genetic predisposition, obesity, and allcause mortality risk in the US: a multiethnic analysis. Diabetes Care. 2016 Apr;39(4):539-46.

7 Lee CM, Woodward M, Pandeya N, Adams R, Barrett-Connor E, Boyko EJ, et al.; Obesity, Diabetes and Cardiovascular Disease Collaboration. Comparison of relationships between four common anthropometric measures and incident diabetes. Diabetes Res Clin Pract. 2017 Oct;132:36-44.

8 Lavie CJ, De Schutter A, Parto P, Jahangir E, Kokkinos P, Ortega FB, et al. Obesity and prevalence of cardiovascular diseases and prognosis—the obesity paradox updated. Prog Cardiovasc Dis. 2016 Mar-Apr;58(5):53747. 
Mosli et al.: Education, Income, and Obesity in Saudi Arabia

9 Hubert HB, Feinleib M, McNamara PM, Castelli WP. Obesity as an independent risk factor for cardiovascular disease: a 26-year follow-up of participants in the Framingham Heart Study. Circulation. 1983 May;67(5): 968-77.

10 Lauby-Secretan B, Scoccianti C, Loomis D, Grosse Y, Bianchini F, Straif K; International Agency for Research on Cancer Handbook Working Group. Body Fatness and Cancer-Viewpoint of the IARC Working Group. N Engl J Med. 2016 Aug;375(8):794-8.

11 Calle EE, Rodriguez C, Walker-Thurmond K, Thun MJ. Overweight, obesity, and mortality from cancer in a prospectively studied cohort of U.S. adults. N Engl J Med. 2003 Apr;348(17):1625-38.

12 Castro-Añón O, Pérez de Llano LA, De la Fuente Sánchez S, Golpe R, Méndez Marote L, Castro-Castro J, et al. Obesity-hypoventilation syndrome: increased risk of death over sleep apnea syndrome. PLoS One. 2015 Feb; 10(2):e0117808.

13 Reyes C, Leyland KM, Peat G, Cooper C, Arden NK, Prieto-Alhambra D. Association between overweight and obesity and risk of clinically diagnosed knee, hip, and hand osteoarthritis: a population-based cohort study. Arthritis Rheumatol. 2016 Aug;68(8):1869-75.

14 Di Angelantonio E, Bhupathiraju SN, Wormser D, Gao P, Kaptoge S, Berrington de Gonzalez A, et al.; Global BMI Mortality Collaboration. Body-mass index and all-cause mortality: individual-participant-data meta-analysis of 239 prospective studies in four continents. Lancet. 2016 Aug;388(10046):776-86.

15 Monteiro CA, Moura EC, Conde WL, Popkin BM. Socioeconomic status and obesity in adult populations of developing countries: a review. Bull World Health Organ. 2004 Dec;82(12):940-6.

16 Popkin BM. Relationship between shifts in food system dynamics and acceleration of the global nutrition transition. Nutr Rev. 2017 Feb;75(2):73-82.

17 Drewnowski A. Nutrient density: addressing the challenge of obesity. Br J Nutr. 2018 Aug; 120 s1:S8-14.

18 Drewnowski A, Darmon N. Food choices and diet costs: an economic analysis. J Nutr. 2005 Apr;135(4):900-4.

19 Blecher E, Liber AC, Drope JM, Nguyen B, Stoklosa M. Peer Reviewed: Global Trends in the Affordability of Sugar-Sweetened Beverages, 1990-2016. Prev Chronic Dis. 2017 May;14:E37.

20 Smith WC, Anderson E, Salinas D, Horvatek R, Baker DP. A meta-analysis of education effects on chronic disease: the causal dynamics of the Population Education Transition Curve. Soc Sci Med. 2015 Feb;127:29-40.

21 Xie B, Gilliland FD, Li YF, Rockett HR. Effects of ethnicity, family income, and education on dietary intake among adolescents. Prev Med. 2003 Jan;36(1):30-40.

22 Wardle J, Parmenter K, Waller J. Nutrition knowledge and food intake. Appetite. 2000 Jun;34(3):269-75.

23 DeNicola E, Aburizaiza OS, Siddique A, Khwaja H, Carpenter DO. Obesity and public health in the Kingdom of Saudi Arabia. Rev Environ Health. 2015;30(3):191-205.

24 Hales CM, Carroll MD, Fryar CD, Ogden CL. Prevalence of obesity among adults and youth: United States, 20152016. NCHS Data Brief. 2017 Oct;(288):1-8.

25 Memish ZA, El-Bcheraoui C, Tuffaha M, Robinson M, Daoud F, Jaber S, et al. Obesity and associated factorsKingdom of Saudi Arabia, 2013. Prev Chronic Dis. 2014;11:140236.

26 Alazzeh AY, AlShammari EM, Smadi MM, Azzeh FS, AlShammari BT, Epuru S, et al. Some Socioeconomic Factors and Lifestyle Habits Influencing the Prevalence of Obesity among Adolescent Male Students in the Hail Region of Saudi Arabia. Children (Basel). 2018 Mar;5(3):39.

27 Alharbi MM, Jackson RT. Factors associated with obesity among Saudi women of reproductive age in Jeddah City. J Obes Overweight. 2017;3(1):106.

28 Lohman TG, Roche AF, Martorell R. Anthropometric standardization reference manual. Champaign (Ill): Human Kinetics Books; 1988.

29 Garawi F, Ploubidis GB, Devries K, Al-Hamdan N, Uauy R. Do routinely measured risk factors for obesity explain the sex gap in its prevalence? Observations from Saudi Arabia. BMC Public Health. 2015 Mar; 15(1): 254.

30 McCarthy MI. Genomics, type 2 diabetes, and obesity. N Engl J Med. 2010 Dec;363(24):2339-50.

31 Devaux M, Sassi F, Church J, Cecchini M, Borgonovi F. Exploring the relationship between education and obesity. OECD Journal: Economic Studies. 2011. Available from: https://doi.org/10.1787/eco_studies-2011$5 \mathrm{~kg} 5825 \mathrm{v} 1 \mathrm{k} 23$.

32 Teachman J. Body weight, marital status, and changes in marital status. J Fam Issues. 2016 Jan;37(1):74-96.

33 Barakat H. The Arab family and the challenge of social transformation. Women Islam Crit Con Soc. 2005;1: 145-65.

34 Saxena R, Voight BF, Lyssenko V, Burtt NP, de Bakker PI, Chen H, et al.; Diabetes Genetics Initiative of Broad Institute of Harvard and MIT, Lund University, and Novartis Institutes of BioMedical Research. Genome-wide association analysis identifies loci for type 2 diabetes and triglyceride levels. Science. 2007 Jun;316(5829): 1331-6.

35 Zeggini E, Weedon MN, Lindgren CM, Frayling TM, Elliott KS, Lango H, et al.; Wellcome Trust Case Control Consortium (WTCCC). Replication of genome-wide association signals in UK samples reveals risk loci for type 2 diabetes. Science. 2007 Jun;316(5829):1336-41. 